\title{
Targeting SIRT1 to inhibit the proliferation of multiple myeloma cells
}

\author{
BO LU* ${ }^{*}$ DENGYANG ZHANG* ${ }^{*}$ XIAOBO WANG, DONGJUN LIN, YUN CHEN and XIAOJUN XU \\ Department of Hematology, The Seventh Affiliated Hospital, Sun Yat-Sen University, \\ Shenzhen, Guangdong 518107, P.R. China
}

Received August 1, 2020; Accepted December 23, 2020

DOI: $10.3892 / \mathrm{ol} .2021 .12567$

\begin{abstract}
Multiple myeloma (MM) is the second most common hematopoietic malignancy and remains an incurable disease. Thus, novel drugs and therapeutic methods are required for patients with $\mathrm{MM}$. The present study aimed to investigate the effect of sirtuin 1 (SIRT1) inhibitor cambinol on the proliferation and apoptosis of myeloma cell lines, RPMI8226 and U266. Moreover, the present study evaluated the underlying molecular mechanisms of proliferation inhibition and apoptosis induced by cambinol. A Cell Counting Kit-8 assay was used to measure the viability of RPMI8226 and U266 cells treated with cambinol. Apoptosis and the cell cycle were analyzed via flow cytometry. The expression levels of caspase-3, poly(ADP-ribose) polymerase 1 (PARP), p53, acetylated p53 (Ac-p53), Bcl-2, cyclin D1 and p21 were detected in cells treated with cambinol using western blot analysis. The results demonstrated that cambinol inhibited the proliferation of RPMI8226 and U266 cells in a time- and dose-dependent manner. Increased apoptosis and $G_{1}$ cell cycle arrest, together with enhanced procaspase-3 degradation and PARP cleavage were identified in cambinol-treated cells compared with controls. Western blotting results also revealed the upregulation of p53 acetylation and p21, as well as the downregulation of Bcl-2 and cyclin D1 in cells treated with cambinol. In conclusion, the present results suggest that cambinol inhibits the proliferation and induces apoptosis in RPMI8226 and U266 cells by regulating acetylation of p53 via the targeting of SIRT1.
\end{abstract}

Correspondence to: Professor Xiaojun Xu, Department of Hematology, The Seventh Affiliated Hospital, Sun Yat-Sen University, Shenzhen, 628 Zhenyuan Road, Xinhu, Guangming, Shenzhen, Guangdong 518107, P.R. China

E-mail: doctorxu@163.com

${ }^{*}$ Contributed equally

Key words: SIRT1 inhibitor, multiple myeloma, cell cycle, apoptosis, Ac-p53

\section{Introduction}

Multiple myeloma (MM) is a malignancy of plasma cells, and is the second most common type of hematopoietic malignancy, accounting for $10-15 \%$ of total hematopoietic cancer types (1). The prevalence of MM increases with age and the median age at diagnosis is 69 years old in the United States (1). Due to the development of novel drugs and therapeutic methods, the overall survival of patients with MM has significantly improved in recent decades (2). However, MM remains an incurable disease. One reason for this is the drug-resistance developed in patients during the treatment $(3,4)$. Therefore, novel drugs and therapeutic methods are required to improve the treatment strategies for patients with MM.

In cancer, epigenetic regulation contributes to reversible modification of chromatin structure and gene transcription (5). Oncogenes are always upregulated or activated whereas tumor suppressor genes are always downregulated or silenced in this process (5). Acetylation/deacetylation is one of the mechanisms that is involved in this regulatory process. Lysine residues of histone or non-histone can be acetylated by histone/protein acetyltransferases, which is contrary to the activity of histone deacetylases (HDAC) (6). Deacetylation of histone or non-histone can lead to transcription silence of genes and deactivation of protein $(6,7)$. In cancer cells, inhibition of HDAC leads to cell cycle arrest and induction of apoptosis. Targeted inhibition of HDAC may therefore be considered as a potential therapeutic method in MM treatment (8).

The silent mating type information regulation 2 homolog (SIRTUIN) family belongs to Class III HDACs and is a group of proteins with nicotinamide adenine dinucleotide (NAD)-dependent deacetylase activity (9). Their substrates include histone and non-histone proteins (9). It has important roles in cancer cell survival and apoptosis by deacetylating key cell signaling molecules and apoptotic related proteins, including TATA binding protein-associated factor 168, p53 and forkhead box O1 (FOXO1) (10). Among the SIRTUIN family, silent mating type information regulation 2 homolog 1 (SIRT1) is the most-studied member in basic and translational oncology research $(11,12)$. Previous studies have reported that SIRT1 contributes to the development of several solid tumors and hematopoietic malignancies $(13,14)$. In addition, small compounds targeting SIRT1 could effectively inhibit the proliferation of tumor cells. Therefore, the present 
study aimed to investigate the antitumor effect of the SIRT1 inhibitor cambinol on MM cells.

\section{Materials and methods}

Reagents and cell lines. MM cell lines RPMI8226 and U266 were ordered from the American Type Culture Collection. A Cell Counting Kit (CCK)-8 assay was purchased from Beyotime Institute of Biotechnology. Cambinol, Annexin V and PI were purchased from Sigma-Aldrich (Merck KGaA). Anti-procaspase-3 (cat. no. 610322; 1:1,000), and poly(ADP-ribose) polymerase 1 (PARP) (cat. no. 556362; $1: 2,000)$ antibodies were purchased from BD Biosciences. The anti- $\beta$-actin antibody (cat.no.ZRB1312; 1:1,000) was purchased from Sigma-Aldrich (Merck KGaA). Anti-p53 (cat. no. 48818; 1:1,000), cleaved caspase 3 (cat. no. 9664; 1:1,000), acetylated p53 (Lys382; Ac-p53) (cat. no.2525; 1:1,000), Bcl-2 (cat. no. 15071; 1:1,000), cyclin D1 (cat. no.2922; 1:1,000) and p21 (cat. no. 2947; 1:1,000) antibodies were purchased from Cell Signaling Technology, Inc. The anti-mouse and rabbit horseradish peroxidase-conjugated secondary antibodies (cat. no. 7076, 7074; 1:5,000) were purchased from Cell Signaling Technology, Inc. Culture RPMI-1640 medium and FBS were purchased from Cytiva. Fluorescence Activated Cell Sorter (FACS) was obtained from BD Biosciences.

Cell viability assay. MM cells were routinely cultured in RPMI-1640 medium supplemented with $10 \% \mathrm{FBS}$ at $37^{\circ} \mathrm{C}$ in a humidified incubator with $5 \% \mathrm{CO}_{2}$. For the proliferation assay, cells were seeded in 96-well plate at a density of $2 \times 10^{4}$ cell/well. The cells were incubated with various concentrations of cambinol $(20,40,80,160$ and $320 \mu \mathrm{M})$ dissolved in DMSO for 24 and $48 \mathrm{~h}$ (at $37^{\circ} \mathrm{C}$ in $5 \% \mathrm{CO}_{2}$ ). Then, $20 \mu \mathrm{lCCK}-8$ solution was added to each well and the cells were incubated at $37^{\circ} \mathrm{C}$ in $5 \% \mathrm{CO}_{2}$ for $4 \mathrm{~h}$ according to the manufacturer's protocol. The absorbance was measured at $450 \mathrm{~nm}$ and values are presented as mean $\pm \mathrm{SD}$.

Cell apoptosis assay. Apoptosis measurement was performed according to the protocol of Annexin V-FITC Apoptosis Detection Kit (Beyotime Institute of Biotechnology). Cells were treated with $80 \mu \mathrm{M}$ cambinol for $48 \mathrm{~h}$ at $37^{\circ} \mathrm{C}$ in $5 \% \mathrm{CO}_{2}$ and were collected via centrifugation $\left(1,000 \mathrm{x}\right.$ g for 5 min at $\left.4^{\circ} \mathrm{C}\right)$. Then, cells were washed once with $1 \mathrm{X}$ washing buffer. Cells were resuspended in $500 \mu \mathrm{l}$ working staining solution and incubated in ice for $5 \mathrm{~min}$, subsequently $5 \mu \mathrm{l}$ Annexin $\mathrm{V}$ was added. Then, $5 \mu$ l PI solution was added to each tube and cells were incubated in ice for $15 \mathrm{~min}$, the cells were detected using FACS. Results are representative of three independent experiments.

Cell cycle analysis. Cells were treated with $80 \mu \mathrm{M}$ cambinol at $37^{\circ} \mathrm{C}$ for $48 \mathrm{~h}$ and were collected via centrifugation $(1,000 \mathrm{x} \mathrm{g}$ for $5 \mathrm{~min}$ at room temperature). The collected cells were resuspended in $70 \%$ ethanol and incubated at $-20^{\circ} \mathrm{C}$ overnight. On the following day, cells were washed twice with PBS and resuspended in $0.5 \mathrm{ml}$ PBS containing $0.1 \%$ Triton X-100, $0.2 \mathrm{mg} / \mathrm{ml}$ DNase-free RNase and $2 \mu \mathrm{g} / \mathrm{ml}$ PI. Cells were incubated on ice in the dark and cell cycle was assessed via FACS within $2 \mathrm{~h}$.

SIRT1 activity assay. SIRT1 activity was analyzed using a fluorogenic SIRT1 assay kit (cat. no. CS1040; Sigma-Aldrich;
Merck KGaA). According to the manufacturer's instructions, whole cell lysate proteins were extracted with RIPA buffer (Beyotime Institute of Biotechnology) and the fluorogenic SIRT1 assay kit was used to perform the assay.

Western blotting. After drug treatment for $48 \mathrm{~h}$, cells in a $60-\mathrm{mm}$ culture dish were washed twice with PBS, lysed in $150 \mu \mathrm{l}$ ice-cold high-efficiency RIPA buffer with the protease inhibitor PMSF $(1 \mathrm{mM})$ for $30 \mathrm{~min}$, then collected to a $1.5 \mathrm{ml}$ tube and centrifuged at $4^{\circ} \mathrm{C} 12,000 \mathrm{x}$ g for $10 \mathrm{~min}$. The protein concentration was quantified in supernatant using a BCA assay kit. The supernatant was mixed with $5 \mathrm{X}$ loading buffer and heated at $100^{\circ} \mathrm{C}$ for $5 \mathrm{~min}$ and samples ( $40 \mu \mathrm{g}$ per lane) were loaded and separated via SDS-PAGE (10\% separating gel). The $0.2-\mu \mathrm{m}$ PVDF membrane was used for protein transfer. Membranes were blocked with 5\% non-fat dry-milk in TBS-Tween-20 (TBST; 0.1\% v/v Tween-20) for $1 \mathrm{~h}$ at room temperature, and then incubated with the primary antibodies overnight at $4^{\circ} \mathrm{C}$. After washing three times with TBST, the membranes were incubated with horseradish peroxidase-conjugated secondary antibodies for $1 \mathrm{~h}$ at room temperature. The membranes were washed three times with TBST, and incubated with chemiluminescent substrates (Santa Cruz Biotechnology, Inc.). Protein semi-quantification was conducted with ImageJ software (National Institutes of Health). Results are representative of three independent experiments.

Statistical analysis. Data are presented as the mean \pm SD. Differences between two groups were determined using unpaired two-sample Student's t-test. Comparisons between multiple groups were determined using a one-way ANOVA with Bonferroni post hoc analysis. Significance was analyzed using GraphPad Prism 6.0 (GraphPad Software, Inc.). $\mathrm{P}<0.05$ was considered to indicate a statistically significant difference.

\section{Results}

Cambinol inhibits the proliferation of RPMI8226 and U266 cells. The inhibitive effect of cambinol on MM cell proliferation was measured using a CCK-8 assay. RPMI8226 and U266 cell lines were treated with different concentrations $(20,40,80,160$ and $320 \mu \mathrm{M})$ of cambinol for 24 and $48 \mathrm{~h}$. It was demonstrated that cambinol inhibited the proliferation of RPMI8226 and U266 cells in a dose- and time-dependent manner. $\mathrm{IC}_{50}$ values of cambinol on RPMI8226 and U266 were $\sim 77.24$ and $79.23 \mu \mathrm{M}$, respectively, following the $48 \mathrm{~h}$ treatment (Fig. 1A and B).

Cambinol induces apoptosis in RPMI8226 and U266 cells. The apoptosis-inducing effect of cambinol on RPMI8226 and U266 cell lines was measured via FACS. MM cells were cultured with $80 \mu \mathrm{M}$ cambinol for $48 \mathrm{~h}$. FACS data demonstrated that the apoptotic rate of RPMI8226 cells increased from $11.43 \%$ in the control group to $55.72 \%$ in the drug-treated group (Fig. 2A), and the rate of apoptosis of U266 cells increased from $6.3 \%$ in control group to $36.71 \%$ in the drug-treated group (Fig. 2B). These data indicate that cambinol significantly induced apoptosis in RPMI8226 and U266 cells.

Cambinol induces cell cycle arrest in RPMI8226 and U266 cells. To examine the effect of cambinol on the cell cycle 
A

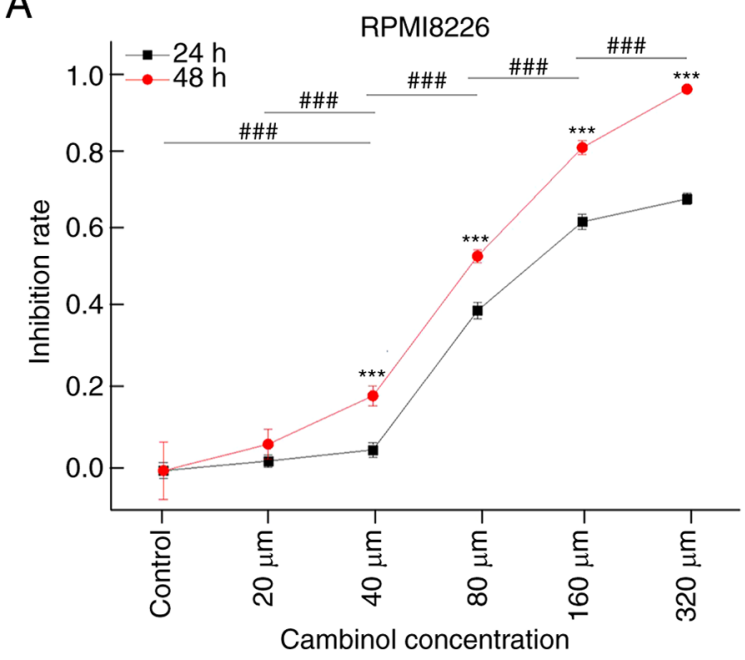

B

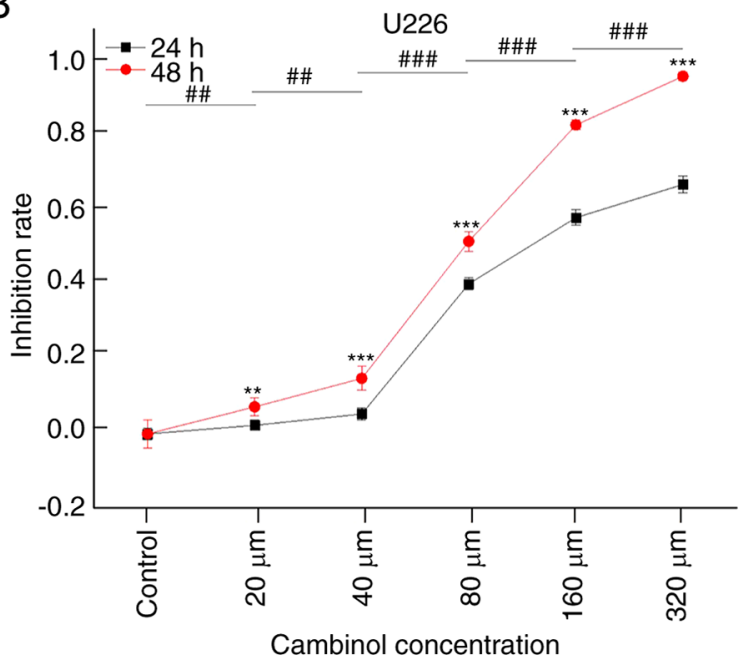

Figure 1. Effect of cambinol on the proliferation of RPMI8226 and U266 cells. RPMI8226 and U266 cells were cultured with cambinol for 24 and 48 h, and then cell proliferation was assessed using a Cell Counting Kit- 8 assay. (A) Proliferation of RPMI8226 cells was significantly inhibited by cambinol in a dose-and time-dependent manner. The $\mathrm{IC}_{50}$ was $77.24 \mu \mathrm{M}$ for $48 \mathrm{~h}$. (B) Proliferation of U266 cells was significantly inhibited by cambinol in a dose-and time-dependent manner. The $\mathrm{IC}_{50}$ was $79.23 \mu \mathrm{M}$ for $48 \mathrm{~h}$. For time-dependent (48 vs. $24 \mathrm{~h}$ ) analysis with the same drug concentration between two groups, an unpaired two-sample t-test was used, ${ }^{* *} \mathrm{P}<0.01,{ }^{* * *} \mathrm{P}<0.001$. For the dose-dependent analysis at $48 \mathrm{~h}$ between multiple groups, one-way ANOVA with Bonferroni post hoc analysis was used, ${ }^{\# \#} \mathrm{P}<0.01,{ }^{\# \# \#} \mathrm{P}<0.001$

A

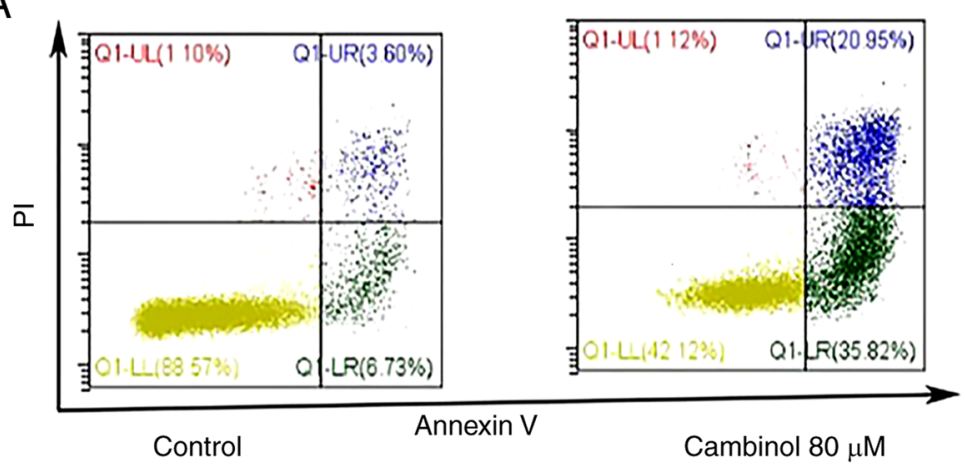

B

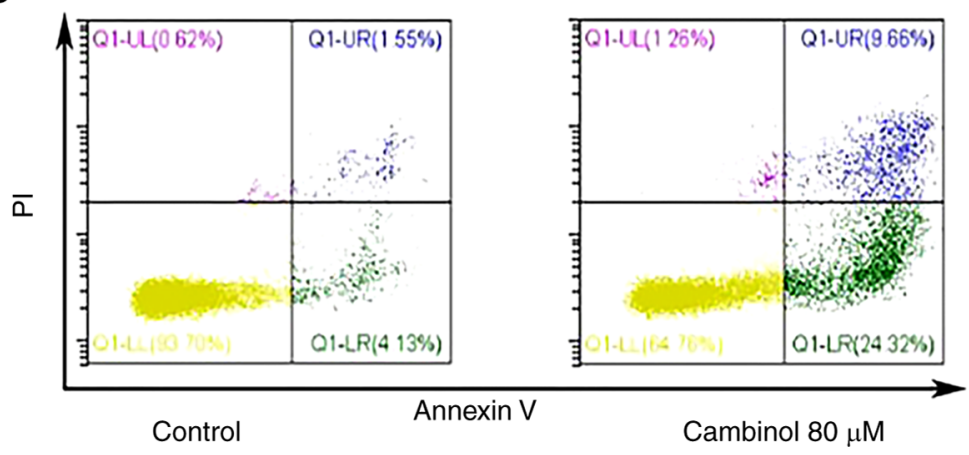

RPMI8226

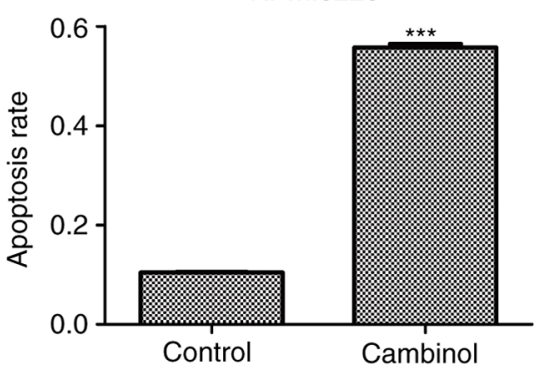

U266

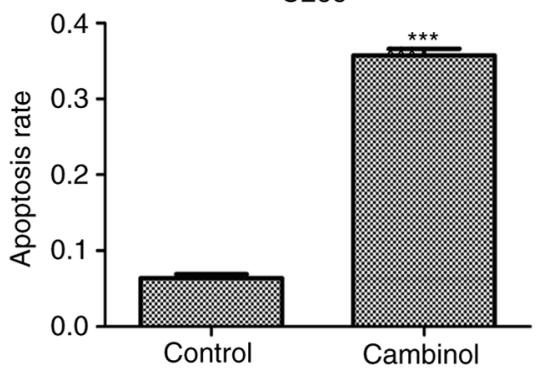

Figure 2. Effect of cambinol on the induction of apoptosis in RPMI8226 and U266 cells. Following 48 h exposure to DMSO vehicle (control) and $80 \mu \mathrm{M}$ cambinol, (A) RPMI8226 and (B) U266 cells were collected and analyzed via flow cytometry using Annexin V-FITC/PI staining. ${ }^{* * *}$ P<0.001.

of RPMI8226 and U266 MM cells, cells were treated with cambinol for $48 \mathrm{~h}$, and then analyzed via FACS after staining with PI. For RPMI8226 cells, the percentage of cells in the $\mathrm{G}_{1}$ phase was $24.23 \%$ in the control group, which increased to $39.73 \%$ in the drug-treated group. For U266 cells, $43.03 \%$ of cells were in the $\mathrm{G}_{1}$ phase in the control group, which increased to $66.33 \%$ in the drug-treated group (Fig. 3).
Inhibition of cambinol on SIRT1 activity and the effect on protein expression levels inRPMI8226 cells. RPMI8226 cells were treated with different concentrations $(0,40,80$ and $160 \mu \mathrm{M}$ ) of cambinol for $48 \mathrm{~h}$ and then lysed with RIPA buffer. SIRT1 activity was analyzed using an SIRT1 assay kit. It was demonstrated that cambinol decreased SIRT1 activity in a dose-dependent manner ( $\mathrm{P}<0.001$; Fig. 4A). Western blotting 

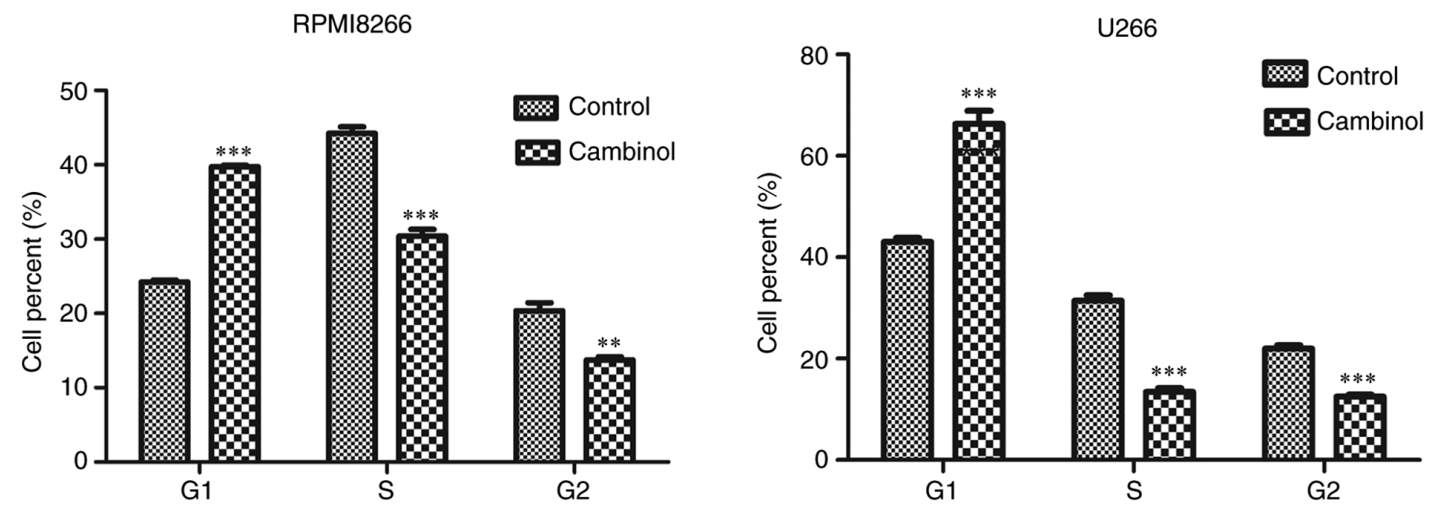

Figure 3. Effect of cambinol on the induction of cell cycle arrest in RPMI8226 and U266 cells. RPMI8226 and U266 cells were treated with $80 \mu$ M cambinol for $48 \mathrm{~h}$, and cells were analyzed via FACS after PI staining. Accumulation in the $\mathrm{G}_{1}$ phase was observed in RPMI8226 and U266 cells treated with cambinol. ${ }^{* * *} \mathrm{P}<0.01$ and ${ }^{* * * *} \mathrm{P}<0.001$.
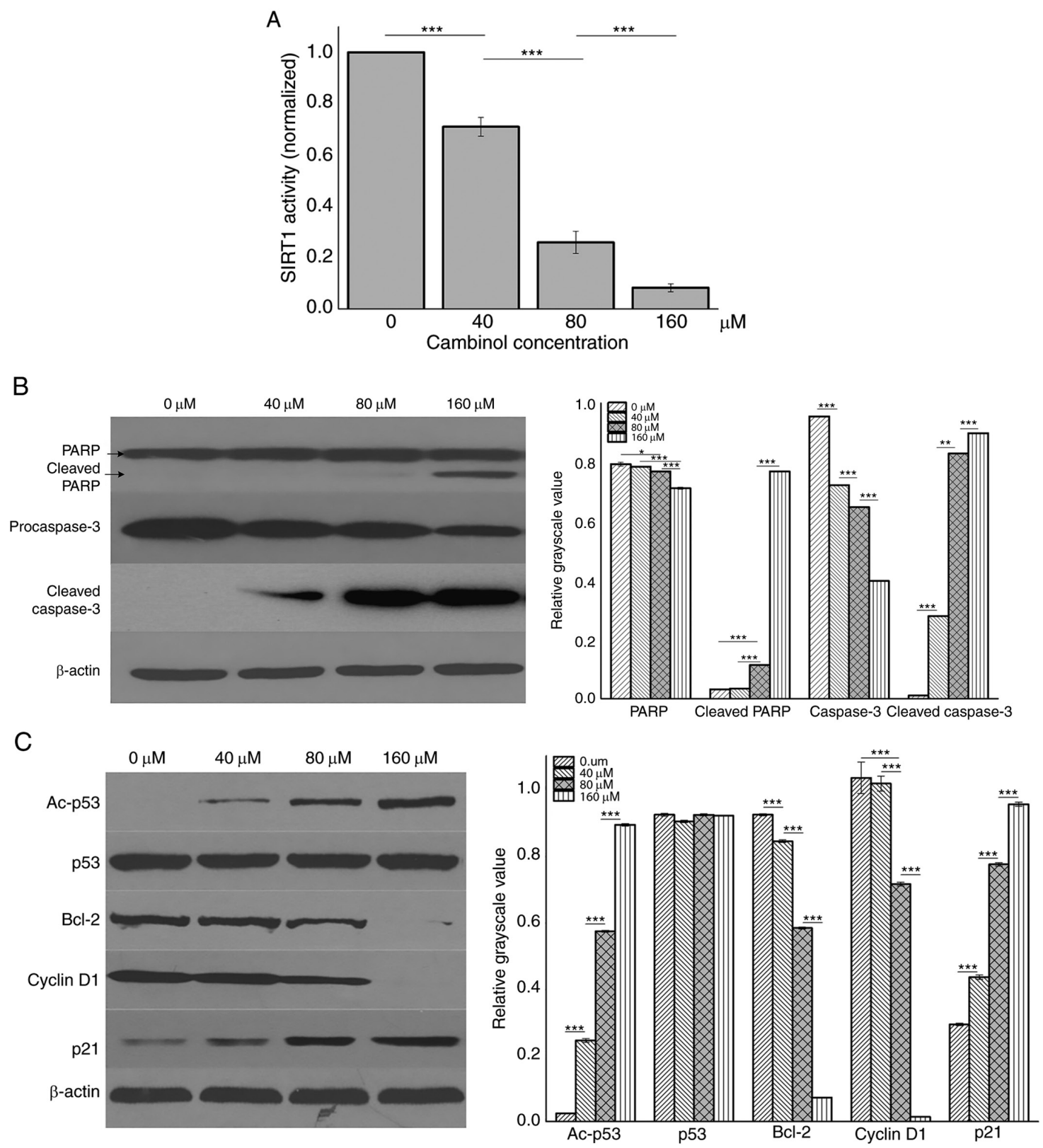

Figure 4. Effect of cambinol on protein expression levels in RPMI8226 cells. Western blotting was performed to assess the protein expression levels in RPMI8226 cells following $48 \mathrm{~h}$ treatment with $0,40,80$ and $160 \mu \mathrm{M}$ cambinol. (A) SIRT1 activity was detected using a SIRT1 Assay kit. (B) Expression levels of PARP and pro-caspase-3. (C) Expression levels of the Ac-p53, p53, Bcl-2, CyclinD1 and p21. $\beta$-actin expression was used as a loading control for each panel. "P<0.05, ${ }^{* *} \mathrm{P}<0.01$ and ${ }^{* * *} \mathrm{P}<0.001$. Ac-p53, Acetylated p53; SIRT1, silent mating type information regulation 2 homolog 1; PARP, poly(ADP-ribose) polymerase 1. 
was used to measure expression levels of PARP, caspase 3, p53, Ac-p53, Bcl-2, cyclin D1 and p21. It was identified that the expression levels of cleaved PARP, cleaved caspase3, Ac-p53 and $\mathrm{p} 21$ were upregulated in a dose-dependent manner, while the expression levels of procaspase $3, \mathrm{Bcl}-2$ and cyclin D1 were downregulated (Fig. 4B and C).

\section{Discussion}

SIRT1 belongs to class III histone deacetylases (HDAC) and it is a homologue protein of yeast silent information regulator 2 (Sir2). The de-acetylation activity of type III HDACs depends on the cofactor NAD, which is dispensable for type I and type II HDACs. The human SIRTUIN family is a homologue to Sir2, and these are highly conservative from bacteria to humans. SIRT1 and SIRT2 of the SIRTUIN family have highly similar sequences, and are associated with cell apoptosis, the cell cycle, DNA repair, DNA recombination and gene silencing $(15,16)$.

SIRT1 deacetylates histone $\mathrm{H} 3$ and histone $\mathrm{H} 4$. It also interacts with transcription factors or co-factors, including p53, FOXO family member, NF- $\kappa$ B, myoblast determination protein 1 , nuclear receptor corepressor, p300 and peroxisome proliferator-activated receptor $\gamma$ coactivator $1-\alpha$, and regulates their transcriptional activity. SIRT1 inhibitors exhibit antitumor activity, which has been observed in cells from breast, thyroid, lung, pancreatic, prostate, hepatitis and colon cancer (17-21). Moreover, SIRT1 has effective antitumor activity against hematological malignancies, such as T/B-cell lymphoma, chronic myeloid leukemia (CML), leukemia and other hematological malignancies $(11,22-26)$. Cambinol is an inhibitor of SIRT1/2 that has been identified to exert antitumor activity and low toxicity in murine models $(27,28)$. The present results demonstrated that cambinol exhibited anti-proliferative effects on RPMI8226 and U266 cell lines that were dose- and time-dependent. Previous studies have reported that the antitumor activity of SIRT1 inhibitors was the result of cell apoptosis and cell cycle arrest (27). In primary exudative lymphoma, SIRT1 inhibitors were found to induce cell apoptosis and cell cycle arrest at the $\mathrm{G}_{1}$ phase (24). When treated with cambinol, the proliferation of hepatic cancer cells is inhibited and the tumor burden in mice is also significantly reduced (27). The present results demonstrated that cambinol suppressed the activity of SIRT1, promoted cell apoptosis and arrested the cell cycle at the $\mathrm{G}_{1}$ phase in $\mathrm{MM}$ cells.

p53 is a tumor suppresser, which is actively involved in tumor occurrence and development. The antitumor function of p53 is mediated via two pathways: Transcription-dependent or -independent signaling pathways. As a transcription factor, p53 can activate the transcription and expression of multiple target genes to regulate cell apoptosis, including growth arrest and DNA damage inducible $\alpha$, murine double minute-2, p21, Bax, fas, insulin-like growth factor-binding protein 3 and TNF receptor superfamily member 10b. p53 can also activate apoptosis by interacting with target proteins directly, which is another effective cell-regulating mechanism (29). p53 can be activated by acetylation (30). Using a SIRT1 inhibitor or gene silencing methods, the protein level of acetylated p53 can be increased in CML cells, and the elimination of CML stem cells can be further potentiated when combined with imatinib (a tyrosine kinase inhibitor) (31). The SIRT1 inhibitor regulates downstream-associated proteins and cyclins through increasing the active form of $\mathrm{p} 53$ and decreasing $\mathrm{Bcl}-2$ protein and cyclin D1. Also, the SIRT1 inhibitor reduces the cell proliferation rate and induces apoptosis in breast cancer cell (32). The present study identified that cambinol increased the acetylation level of p53, which further upregulates p21 protein levels, subsequently inhibiting cyclin D1. In addition, the results indicated that increased levels of acetylated p53 was a possible mechanism for the inhibitory effect of cambinol on MM cells.

MM is currently recognized as an incurable tumor type, due to drug resistance. The application of novel drugs is an effective method to improve the survival of patients with MM. Cambinol was investigated to inhibit cell viability in hepatocellular carcinoma, breast cancer, prostate cancer and human glioma cell lines (33-36), and also exhibits antitumor activity. According to the literature, to the best of our knowledge, no studies have examined the effect and mechanism of cambinol in MM cells. The present study demonstrated the antitumor activity of cambinol on MM cells and described the potential mechanism. Moreover, further studies to increase the potency and selectivity towards SIRT1 or SIRT2 for enhanced their antitumor efficacy are underway. Cambinol analogs may be beneficial for sensitizing tumor cells to other chemotherapeutic agents $(37,38)$. Thus, cambinol and its analogs are promising antitumor agents for MM.

In conclusion, the present study investigated the effect of cambinol on MM cell lines-RPMI8226 and U266, and found that cambinol can inhibit proliferation, and induce apoptosis of MM cells. The possible underlying mechanism of cambinol on MM cells involves the upregulation of acetylation p53 protein through inhibition of SIRT1. The results of this study provide evidence for the further clinical use of cambinol or its analogs in treating patients with MM.

\section{Acknowledgements}

Not applicable.

\section{Funding}

This study was supported by the Sanming Project of Medicine in Shenzhen (grant no. SZSM201911004) and the hospital research fund of The Seventh Affiliated Hospital Sun Yat-sen University (grant no. ZSQYLCKYJJ202027).

\section{Availability of data and materials}

The datasets used and/or analyzed during the present study are available from the corresponding author on reasonable request.

\section{Authors' contributions}

$\mathrm{XX}$ and BL conceived and designed all the experiments. BL and DZ performed the experiments. XW, YC and DL analyzed the experimental data. BL and DZ contributed to manuscript preparation, writing, editing and revision. All authors read and approved the final version of the manuscript.

\section{Ethics approval and consent to participate}

Not applicable. 


\section{Patient consent for publication}

Not applicable.

\section{Competing interests}

The authors declare that they have no competing interests.

\section{References}

1. Lynch HT, Watson P, Tarantolo S, Wiernik PH, Quinn-Laquer B Isgur Bergsagel K, Huiart L, Olopade OI, Sobol H, Sanger W, et al: Phenotypic heterogeneity in multiple myeloma families. J Clin Oncol 23: 685-693, 2005 .

2. Terpos E and International Myeloma Society: Multiple myeloma: Clinical updates from the American Society of hematology annual meeting, 2017. Clin Lymphoma Myeloma Leuk 18 321-334, 2018

3. Robak P, Drozdz I, Szemraj J and Robak T: Drug resistance in multiple myeloma. Cancer Treat Rev 70: 199-208, 2018.

4. Xu XH, Liu J, Shen CY, Ding LL, Zhong F, Ouyang Y, Wang YC and $\mathrm{He}$ S: The role of ubiquitin-specific protease 14 (USP14) in cell adhesion-mediated drug resistance (CAM-DR) of multiple myeloma cells. Eur J Haematol 98: 4-12, 2017.

5. Liu M, Jiang L and Guan XY: The genetic and epigenetic alterations in human hepatocellular carcinoma: A recent update. Protein Cell 5: 673-691, 2014.

6. Khochbin S, Verdel A, Lemercier C and Seigneurin-Berny D: Functional significance of histone deacetylase diversity. Curr Opin Genet Dev 11: 162-166, 2001.

7. Tang Y, Zhao W, Chen Y, Zhao Y and Gu W: Acetylation is indispensable for p53 activation. Cell 133: 612-626, 2008.

8. Conte M, De Palma R and Altucci L: HDAC inhibitors as epigenetic regulators for cancer immunotherapy. Int J Biochem Cell Biol 98: 65-74, 2018

9. Jin X, Wei Y, Xu F, Zhao M, Dai K, Shen R, Yang S and Zhang N: SIRT1 promotes formation of breast cancer through modulating Akt activity. J Cancer 9: 2012-2023, 2018

10. Kumar A and Chauhan S: How much successful are the medicinal chemists in modulation of SIRT1: A critical review. Eur J Med Chem 119: 45-69, 2016

11. Roth M, Wang Z and Chen WY: Sirtuins in hematological aging and malignancy. Crit Rev Oncog 18: 531-547, 2013.

12. Hwang ES and Song SB: Nicotinamide is an inhibitor of SIRT1 in vitro, but can be a stimulator in cells. Cell Mol Life Sci 74: 3347-3362, 2017

13. Li L and Bhatia R: Role of SIRT1 in the growth and regulation of normal hematopoietic and leukemia stem cells. Curr Opin Hematol 22: 324-329, 2015

14. Tae IH, Park EY, Dey P, Son JY, Lee SY, Jung JH, Saloni S, Kim MH and Kim HS: Novel SIRT1 inhibitor 15 -deoxy- $\Delta 12,14$ prostaglandin $\mathrm{J} 2$ and its derivatives exhibit anticancer activity through apoptotic or autophagic cell death pathways in SKOV3 cells. Int J Oncol 53: 2518-2530, 2018

15. Mellini P, Valente S and Mai A: Sirtuin modulators: An updated patent review (2012-2014). Expert Opin Ther Pat 25: 5-15, 2015.

16. Hirsch BM and Zheng W: Sirtuin mechanism and inhibition: Explored with N(e)-acetyl-lysine analogs. Mol Biosyst 7: 16-28, 2011.

17. Panathur N, Gokhale N, Dalimba U, Koushik PV, Yogeeswari P and Sriram D: New indole-isoxazolone derivatives: Synthesis, characterisation and in vitro SIRT1 inhibition studies. Bioorg Med Chem Lett 25: 2768-2772, 2015.

18. Oon CE, Strell C, Yeong KY, Ostman A and Prakash J: SIRT1 inhibition in pancreatic cancer models: Contrasting effects in vitro and in vivo. Eur J Pharmacol 757: 59-67, 2015.

19. Yao Y, Liu T, Wang X and Zhang D: The contrary effects of Sirt1 on MCF7 cells depend on CD36 expression level. J Surg Res 238 248-254, 2019.

20. Karbasforooshan H, Roohbakhsh A and Karimi G: SIRT1 and microRNAs: The role in breast, lung and prostate cancers. Exp Cell Res 367: 1-6, 2018

21. Ghosh A, Sengupta A, Seerapu GPK, Nakhi A, Shivaji Ramarao EVV, Bung N, Bulusu G, Pal M and Haldar D: A novel SIRT1 inhibitor, 4bb induces apoptosis in HCT116 human colon carcinoma cells partially by activating p53. Biochem Biophys Res Commun 488: 562-569, 2017.
22. Zhou L, Wang Q, Chen X, Fu L, Zhang X, Wang L, Deng A, Li D, Liu J, Lv N, et al: AML1-ETO promotes SIRT1 expression to enhance leukemogenesis of $\mathrm{t}(8 ; 21)$ acute myeloid leukemia. Exp Hematol 46: 62-69, 2017.

23. Sharma VK, Raimondi V, Ruggero K, Pise-Masison CA, Cavallari I, Silic-Benussi M, Ciminale V and D'Agostino DM: Expression of miR-34a in T-cells infected by human T-Lymphotropic Virus 1. Front Microbiol 9: 832, 2018.

24. He M, Tan B, Vasan K, Yuan H, Cheng F, Ramos da Silva S, Lu C and Gao SJ: SIRT1 and AMPK pathways are essential for the proliferation and survival of primary effusion lymphoma cells. J Pathol 242: 309-321, 2017.

25. Bhalla $S$ and Gordon LI: Functional characterization of NAD dependent de-acetylases SIRT1 and SIRT2 in B-cell chronic lymphocytic leukemia (CLL). Cancer Biol Ther 17: 300-309, 2016.

26. Kim HB, Lee SH, Um JH, Oh WK, Kim DW, Kang CD and Kim SH: Sensitization of multidrug-resistant human cancer cells to Hsp90 inhibitors by down-regulation of SIRT1. Oncotarget 6: 36202-36218, 2015

27. Portmann S, Fahrner R, Lechleiter A, Keogh A, Overney S, Laemmle A, Mikami K, Montani M, Tschan MP, Candinas D and Stroka D: Antitumor effect of SIRT1 inhibition in human HCC tumor models in vitro and in vivo. Mol Cancer Ther 12: 499-508, 2013

28. Heltweg B, Gatbonton T, Schuler AD, Posakony J, Li H, Goehle S, Kollipara R, Depinho RA, Gu Y, Simon JA and Bedalov A: Antitumor activity of a small-molecule inhibitor of human silent information regulator 2 enzymes. Cancer Res 66: 4368-4377, 2006

29. Huang J: Current developments of targeting the p53 signaling pathway for cancer treatment. Pharmacol Ther: Oct 29, 2020 (Epub ahead of print). doi: 10.1016/j.pharmthera.2020.107720.

30. Brooks CL and Gu W: New insights into p53 activation. Cell Res 20: 614-621, 2010

31. Li L, Wang L, Li L, Wang Z, Ho Y, McDonald T, Holyoake TL, Chen $\mathrm{W}$ and Bhatia R: Activation of $\mathrm{p} 53$ by SIRT1 inhibition enhances elimination of CML leukemia stem cells in combination with imatinib. Cancer Cell 21: 266-281, 2012.

32. Peck B, Chen CY, Ho KK, Di Fruscia P, Myatt SS, Coombes RC, Fuchter MJ, Hsiao CD and Lam EW: SIRT inhibitors induce cell death and p53 acetylation through targeting both SIRT1 and SIRT2. Mol Cancer Ther 9: 844-855, 2010.

33. Ceballos MP, Decandido G, Quiroga AD, Comanzo CG, Livore VI, Lorenzetti F, Lambertucci F, Chazarreta-Cifre L, Banchio C, Alvarez ML, et al: Inhibition of sirtuins 1 and 2 impairs cell survival and migration and modulates the expression of P-glycoprotein and MRP3 in hepatocellular carcinoma cell lines. Toxicol Lett 289: 63-74, 2018.

34. Dykes SS, Friday E, Pruitt K and Cardelli JA: The histone deacetylase inhibitor cambinol prevents acidic pHe-induced anterograde lysosome trafficking independently of sirtuin activity. Biochem Biophys Rep 3: 83-93, 2015.

35. Simmons GE Jr, Pandey S, Nedeljkovic-Kurepa A, Saxena M, Wang A and Pruitt K: Frizzled 7 expression is positively regulated by SIRT1 and $\beta$-catenin in breast cancer cells. PLoS One 9: e98861, 2014.

36. Holloway KR, Barbieri A, Malyarchuk S, Saxena M, Nedeljkovic-Kurepa A, Cameron Mehl M, Wang A, Gu X and Pruitt K: SIRT1 positively regulates breast cancer associated human aromatase (CYP19A1) expression. Mol Endocrinol 27: 480-490, 2013

37. Botta L, Filippi S, Bizzarri BM, Meschinia R, Caputoa M, Proietti-De-Santisa L, Isideb C, Nebbiosob A, Gualandia G and Saladinoa R: Oxidative nucleophilic substitution selectively produces cambinol derivatives with antiproliferative activity on bladder cancer cell lines. Bioorg Med Chem Lett 29: 78-82, 2019.

38. Mahajan SS, Scian M, Sripathy S, Posakony J, Lao U, Loe TK, Leko V, Thalhofer A, Schuler AD, Bedalov A and Simon JA: Development of pyrazolone and isoxazol-5-one cambinol analogues as sirtuin inhibitors. J Med Chem 57: 3283-3294, 2014

(i) $\ominus$ This work is licensed under a Creative Commons Attribution-NonCommercial-NoDerivatives 4.0 International (CC BY-NC-ND 4.0) License. 